Research Article

\title{
Protective Effect of Compound Formula Rehmannia against Neurotoxicity and Apoptosis Induced by $\alpha$-Syn in In Vivo and In Vitro Models of Parkinson's Disease
}

\author{
Long Teng $\mathbb{D},{ }^{1}$ Minchun Yang, ${ }^{1}$ Xiaoqing Jin $\mathbb{D}^{1},{ }^{1}$ Lu Qian, ${ }^{1}$ Weijia Yang $\mathbb{D},{ }^{1}$ \\ Xuanxuan Ren, ${ }^{1}$ and Qing $\mathbf{Q u}{ }^{2}$ \\ ${ }^{1}$ Department of Internal Medicine of Traditional Chinese Medicine, Zhejiang Hospital, Hangzhou, Zhejiang 310030, China \\ ${ }^{2}$ Department of Massage, Zhejiang Hospital, Hangzhou, Zhejiang 310030, China \\ Correspondence should be addressed to Long Teng; tlzjyy@126.com
}

Received 8 April 2020; Revised 19 June 2020; Accepted 11 July 2020; Published 17 August 2020

Academic Editor: José L. Rios

Copyright (c) 2020 Long Teng et al. This is an open access article distributed under the Creative Commons Attribution License, which permits unrestricted use, distribution, and reproduction in any medium, provided the original work is properly cited.

\begin{abstract}
The present study aimed to investigate the protective effect of compound formula Rehmannia (CFR) against the development of Parkinson's disease (PD). After the in vivo and in vitro models of PD were established with overexpression $\alpha$-syn induced, CFR was administrated into the PD model rats for 6 weeks or SK-N-SH cells with coincubation for 48 h. Apomorphine-induced rotation test, CCK8 assay, TUNEL assay, immunofluorescence staining, and western blot assay were performed to evaluate the behavioral changes, cell viability, cell apoptosis, $\alpha$-syn, GSK-3 $\beta$, P-GSK-3 $\beta$ (Ser9), P-GSK-3 $\beta$ (Tyr216), and $\beta$-catenin expression in PD rats or SK-N-SH cells. PD rat behavior results showed that the rotation numbers were significantly decreased in the CFR treatment group comparing with the AAV- $\alpha$-syn PD model group. The cell viability suppressed by $\mathrm{H}_{2} \mathrm{O}_{2}$ and $\alpha$-syn in SK-N-SH model cells was also significantly improved with CFR administration. Cell apoptosis and $\alpha$-syn overexpression observed in PD rats and SK-N-SH cells were also inhibited by CFR treatment. Furthermore, the protein expression of $\alpha$-syn, GSK-3 $\beta$, P-GSK-3 $\beta$ (Ser9), P-GSK-3 $\beta$ (Tyr216), and $\beta$-catenin in in vivo and in vitro was also significantly regulated by CFR. The present study suggested that CFR may be considered as a potential neuroprotective agent against $\mathrm{PD}$, and this application will require further investigation.
\end{abstract}

\section{Introduction}

Parkinson's disease (PD) is a common neurodegenerative disease prevalent in middle-aged and elderly populations. Clinical features of PD are a range of motor and nonmotor symptoms, such as static tremor, bradykinesia, rigidity, postural balance disorder, depression, abnormal sleep behavior, and memory loss [1]. The epidemiological studies report that the prevalence of $\mathrm{PD}$ is about $0.3 \%$, while the incidence is doubled with the incidence of $1 \%$ to $2 \%$ in the elders over 65 years old and 3\% to $5 \%$ in the elders over 85 years old [2]. PD is characterized by the progressive degeneration of dopaminergic neurons in the substantia nigra pars compacta ( $\mathrm{SNpc}$ ) and loss of dopamine (DA) in the striatum [3]. Additionally, oxidative stress and mitochondrial dysfunction are also involved in the degeneration and loss of dopaminergic neurons in the substantia nigra. DA replacement therapy represented by levodopa (L-Dopa) remains the most applied method in PD treatment. However, still PD cannot be cured completely yet, and more importantly, the side effects of L-Dopa gradually appear with the prolongation of time. Talking of the side effects, the most seriuos one is the L-Dopa-induced dyskinesia, the clinical manifestation mainly resembles dance, which seriously affects the quality of daily life of PD patients and creates an escalating burden on the family and society [4].

The pathogenesis of PD is complex, and the first protein identified to be associated with PD is $\alpha$-synuclein ( $\alpha$-syn), 
which is abundant in neuronal inclusions termed Lewy bodies and Lewy neurites. The mutation or overaccumulation of $\alpha$-syn causes abnormal aggregation and misfolding, which damage the normal physiological functions of cells, promote cell death, inhibit the release of DA, and increase the likelihood of neurodegenerative changes [5]. Due to the close correlation between $\alpha$-syn and PD, $\alpha$-syn is considered as a potential therapeutic target for neurodegenerative diseases, especially for PD. And glycogen synthase kinase-3 $\beta$ (GSK-3 $\beta$ ), one of the GSK-3 isomers, is directly associated with the neuronal apoptosis, and its inhibition also affects the expression of $\alpha$-syn [6]. It stimulates cell survival transcription factors such as CRE-binding protein (CREB), nuclear factor of the activated T-cell (NFAT) protein family, and $\beta$-catenin. Study on differentiated SH-SY5Y cells in oxygen and glucose deprivation (OGD) model also found that GSK- $3 \beta$ inhibitors had antiapoptotic activity, as evidenced by reduced caspase- 3 enzyme activity and increased survivin transcription, and GSK-3 $\beta$ also upregulated survival AKT1/ GSK-3 $\beta / \beta$-catenin pathway, GAP43, Ngn1, and NeuroD2 gene transcription to maintain neuronal survival [7]. However, the effect of $\alpha$-syn overexpression on GSK-3 $\beta$ activity and the role of the GSK-3 $\beta / \beta$-catenin signaling pathway in neurodegenerative diseases are still unclear.

Traditional Chinese medicine (TCM) combined with Western medicine has advantages of "effect-enhancing and toxicity-reducing" in the treatment of PD [8]. TCM can attenuate the progression of the disease and the occurrence of the complications to a certain extent, which play a therapeutic role for PD patients. The compound formula Rehmannia (CFR) is a formula based on the holistic view and syndrome differentiation theory of TCM; the protective effect against PD is also proved through long-term clinical and experimental studies [9]. In this study, based on the previous research, we suspected that neuroprotective effect of CFR against PD might be correlated with $\alpha$-syn and GSK- $3 \beta / \beta$-catenin signaling, in vivo and in vitro models of PD induced with $\alpha$-syn were established, and neuroprotective effect and possible mechanism of CFR were also explored.

\section{Materials and Methods}

2.1. CFR Decoction and CFR-Contained Serum Preparation. CFR, composed by prepared Rehmannia glutinosa $15 \mathrm{~g}$, Concha Margaritifera Usta $30 \mathrm{~g}$, fried Salvia miltiorrhiza $9 \mathrm{~g}$, Acorus gramineus Soland $12 \mathrm{~g}$, and green tea $6 \mathrm{~g}$, was boiled to obtain the CFR decoction with a concentration of $5.18 \mathrm{~g} /$ $\mathrm{ml}$ for further in vivo experiment. The CFR decoction preparation was processed by Hangzhou Huadong Medicinal Materials Co., Ltd. (Zhejiang, China). SD rats weighing 250-300 g were intragastric administrated with CFR at a dose of $9 \mathrm{ml} / \mathrm{kg} / \mathrm{d}$. After treatment for 3 days, blood was obtained at $1 \mathrm{~h}$ after the last administration and centrifuged at 2,000 r. $\mathrm{min}^{-1}$ for $5 \mathrm{~min}$ at room temperature. The upper serum fraction was isolated and further inactivated at $56^{\circ} \mathrm{C}$ for $30 \mathrm{~min}$. The serum was then filtered through a $0.22 \mu \mathrm{m}$ filter, and these obtained CFR-contained serum samples were stored at $-70^{\circ} \mathrm{C}$ for further in vitro experiment.
2.2. Animals. Male SD rats, weighing 250-300 g, were purchased from Shanghai Sipper-BK Experimental Animals Co., Ltd. (Shanghai, China; certification no. SCXK: 2013-0016). All rats were housed in cages under controlled condition of temperature $\left(22 \pm 2^{\circ} \mathrm{C}\right)$, humidity (50\%-60\%), and $12 \mathrm{~h}$ light/dark cycle lighting with food and water freedom in Zhejiang Traditional Chinese Medicine University, Animal Experimental Research Center (Zhejiang, China; certification no. SYXK: 20130184). All animal procedures were approved by the animal ethics committee of Zhejiang Traditional Chinese Medicine University.

2.3. Surgical Procedure and Experiment Design. SD rats were randomly assigned into five groups with 10 rats in each group. Control group: rats were fixed to a stereotaxic frame without any surgical procedures; sham-operated group: rats were injected with $0.2 \%$ vitamin c; negative control group: rats were injected with AAV empty vector and intragastric injected with normal saline for 6 weeks; PD model group: rats were injected with $\mathrm{AAV}-\alpha$-syn and intragastric injected with normal saline for 6 weeks; and PD + CFR group: rats were injected with AAV- $\alpha$-syn and intragastric administrated with CFR at $9 \mathrm{ml} / \mathrm{kg}$ with 2 times/d for 6 weeks. PD model surgical procedures were performed according to the previous described study with slight modifications [10]. AAV- $\alpha$-syn and AAV empty vector were purchased from Genechem (China). After the anesthesia with intraperitoneal injection of $3 \%$ pentobarbital sodium $40 \mathrm{mg} / \mathrm{kg}$, SD rats were fixed to a stereotaxic frame, and then $10 \mu \mathrm{l}$ of AAV- $\alpha$-syn, AAV empty vector, or $0.2 \%$ vitamin $c$ were injected to the substantia nigra. The injections were carried out to the substantia nigra at the following coordinates: anteriorposterior: $5.2 \mathrm{~mm}$, medial-lateral: $1.0 \mathrm{~mm}$, dorsal-ventral: $9.0 \mathrm{~mm}$ below the dural surface; anterior-posterior: $5.2 \mathrm{~mm}$, medial-lateral: $2.5 \mathrm{~mm}$, and dorsal-ventral: $8.5 \mathrm{~mm}$ below the dural surface [11]. Vector solutions were infused at a rate of $0.2 \mathrm{ml} / \mathrm{min}$, and the needle was left in place for an additional $35 \mathrm{~min}$ before it was slowly retracted.

2.4. Apomorphine-Induced Rotation Test. Rotation test is the most commonly used method for assessing functional efficacy of the PD animal model. In this study, rotation test was performed according to a previous study [12]. In brief, the rats in different groups were injected with apomorphine (the dopamine agonist) $2 \mathrm{mg} / \mathrm{kg}$, i.p., and the number of contralateral rotations (turn unilaterally 360 degrees) was counted for a period of $30 \mathrm{~min}$.

2.5. Brain Tissue Preparation. At the end of the animal experiment, all rats were anaesthetized with $40 \mathrm{mg} / \mathrm{kg} 3 \%$ pentobarbital sodium and exsanguination. Subsequently, about $50 \mathrm{ml}$ saline was perfused through the ascending aorta, and then brain tissues were dissected, fixed in $4 \%$ paraformaldehyde for $2 \mathrm{~h}$ and cryoprotected overnight in sucrose. Brain tissues were sectioned on a freezing microtome (Leica) at a thickness of $35 \mu \mathrm{m}$ carefully. Other brain tissue 
samples were stored at $-80^{\circ} \mathrm{C}$ for further western blot experiment.

2.6. SK-N-SH Cell Culture and Treatment. SK-N-SH human neuroblastoma cells were purchased from iCell Bioscience, Inc. (Shanghai, China), cultured in DMEM containing 10\% fetal bovine serum, 100,000 U/mL penicillin, and 100,000 $\mu \mathrm{g} /$ $\mathrm{L}$ streptomycin, and maintained in a humidified incubator at $37^{\circ} \mathrm{C}$ with $5 \% \mathrm{CO}_{2}$. For generation of the $\alpha$-syn overexpression cell line, SK-N-SH cells were transfected with $\alpha$-syn plasmids or empty control plasmids in six-well plates with Lipofectamine 2000 according to the manufacturer's protocol. Afterwards, cells were treated and incubated with $300 \mu \mathrm{M} \mathrm{H}_{2} \mathrm{O}_{2}$ for 30 min to induce cell injury followed by treatment with low or high dose of CFR-contained serum $(5 \%, 10 \%)$ for $48 \mathrm{~h} \mathrm{[13].}$

2.7. CCK8 Assay. CCK8 assay was used to evaluate the effect of the CFR on the cell viability against $\mathrm{H}_{2} \mathrm{O}_{2}$ and $\alpha$-syn. SK$\mathrm{N}$-SH cells were plated into 96-well plates and incubated for $24 \mathrm{~h} 37^{\circ} \mathrm{C}$ with $5 \% \mathrm{CO}_{2}$. After that, $5 \%$ or $10 \%$ CFR-contained serum was added to the SK-N-SH cells and coincubated for 24 and $48 \mathrm{~h}$. Then, $10 \mu \mathrm{l}$ of CCK8 solution (Beyotime, China) was added to each well and further incubated for $4 \mathrm{~h}$. Finally, the OD value was measured in a microplate reader (CMaxPlus, SpectraMax) at $450 \mathrm{~nm}$.

2.8. TUNEL Assay. TUNEL assay was performed to assess the protective effect of CFR against $\alpha$-syn-induced apoptosis in in vivo and vitro models of PD. In brief, TUNEL staining was performed using the TUNEL kit as instructed by the manufacturer (BBI, China). Brain tissue sections or SK-NSH cells were transferred to the TUNEL reaction mixture for incubation; subsequently, the tissues or cells were subjected to 4',6-diamidino-2-phenylindole (DAPI) for further staining. After that, all samples were visualized under an inverted microscope equipped with fluorescence (Zeiss, Germany), and three random fields were selected per sample.

2.9. Immunofluorescence Staining. To assess the expression of $\alpha$-syn in SK-N-SH cells, immunofluorescence staining was conducted. SK-N-SH cells were fixed with $4 \%$ paraformaldehyde and washed with PBS 3 times, then permeabilized with $0.1 \%$ Triton X-100 for $15 \mathrm{~min}$, and washed with PBS 3 times; 2\% BSA was further added for $1 \mathrm{~h}$ of blocking and then washed with PBS 3 times. After that, cells were incubated with the primary anti- $\alpha$-syn antibody overnight at $4^{\circ} \mathrm{C}$, washed with PBS 3 times, and was followed by incubation with DAPI for $1 \mathrm{~h}$ at room temperature. Brain tissue images and cell images were obtained with an inverted microscope equipped with fluorescence.

2.10. Western Blot Assay. Rat brain tissues or SK-N-SH cells were collected and extracted with lysis buffer to obtain total protein. The protein samples were separated on 5\% SDS-
PAGE and then transferred to PVDF membranes. After blocked in $5 \%$ nonfat milk for $2 \mathrm{~h}$ at room temperature, the membranes were washed with TBST 3 times and then incubated with the primary antibodies against $\alpha$-syn, GSK-3 $\beta$, P-GSK-3 $\beta$ (Ser9), P-GSK-3 $\beta$ (Tyr216), and $\beta$-catenin (Abcam, USA) at $4^{\circ} \mathrm{C}$ overnight. After 3 times washing with TBST, the membranes were further incubated with secondary antibodies for $1 \mathrm{~h}$ at room temperature. The protein blots were visualized by using an ECL system and quantified with ImageJ software; GAPDH was used as a loading control to normalize the band density.

2.11. Statistical Analysis. All data were presented as mean \pm standard deviation (SD). The collected data were subjected to one-way ANOVA followed by LSD test to analyse the statistical differences between groups. $P<0.05$ was considered as statistically significant.

\section{Results}

3.1. Behavioral Assessment for the Effect of CFR on the PD Model Rat. As observed, the control group showed an average of $25.7 \pm 6.11 / 30 \mathrm{~min}$ rotation number, and the shamoperated group showed an average of $20 \pm 2.82 / 30 \mathrm{~min}$ rotation number (Figure 1). However, in the PD model group, the average rotation number was $219 \pm 13.52$ in $30 \mathrm{~min}$ and was significantly increased compared with the control group $(P<0.01)$. Furthermore, with the administration of CFR for $\mathrm{PD}$ rats, the rotation number was $150 \pm 20.1$ in average and was decreased significantly compared with the PD model group $(P<0.01)$, but rotation numbers between $\mathrm{PD}+\mathrm{CFR}$ and control groups were also statistically significant $(P<0.01)$.

\subsection{Effect of CFR on the Apoptosis of the Substantia Nigra and} Striatum Tissues of the PD Model Rat. The antiapoptosis effect of CFR on the PD model rat was assessed using TUNEL assay. As shown in Figure 2, TUNEL-positive cells in the control group, sham-operated group, and negative group of the brain substantia nigra tissues could be observed with weak immunofluorescence intensity. TUNEL-positive cells in the PD model group were significantly increased compared with the control group, thus inducing the cellular apoptosis $(P<0.01)$. And CFR administration obviously reduced the cellular apoptosis with decreased amount of the TUNEL-positive cells compared with the PD model group $(P<0.05)$. In addition, similar tendency can also be observed for the antiapoptosis effect of CFR on PD model rat striatum tissues. TUNEL-positive cells in the PD model group were obviously increased compared with the control group, and the CFR treatment for the PD rat model decreased the TUNEL-positive cells compared with the model group $(P<0.01)$.

3.3. Effect of CFR on the Protein Expression of $\alpha$-Syn, GSK-3 $\beta$, $P$-GSK-3 $\beta$, and $\beta$-Catenin in the PD Model Rat. Western blot analysis was performed to determine the expression of 


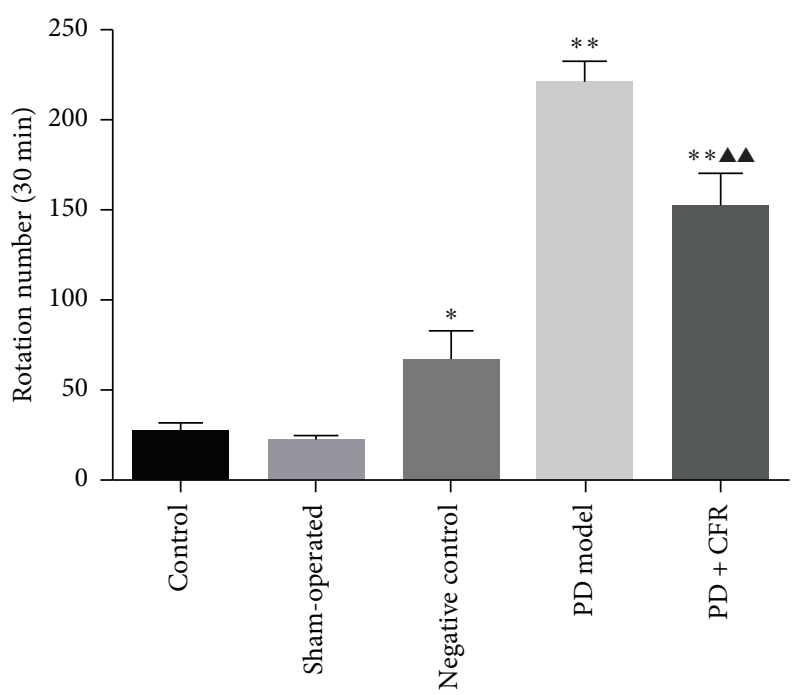

FIGURE 1: Effect of CFR on the rotation numbers of the rats $(n=10)$. Control group: without any surgical procedures or treatment, shamoperated group: $0.2 \%$ vitamin c, negative control group: AAV empty vector, PD model group: AAV- $\alpha$-syn, and PD + CFR group: AAV$\alpha$-syn + CFR, $9 \mathrm{ml} / \mathrm{kg}, 2$ times/d, 6 weeks. Compared with the control group, ${ }^{*} P<0.05$ and ${ }^{* *} P<0.01$; compared with the PD model group, $\triangle P<0.05$ and $\boldsymbol{\Delta \Lambda}^{\Delta} P<0.01$.

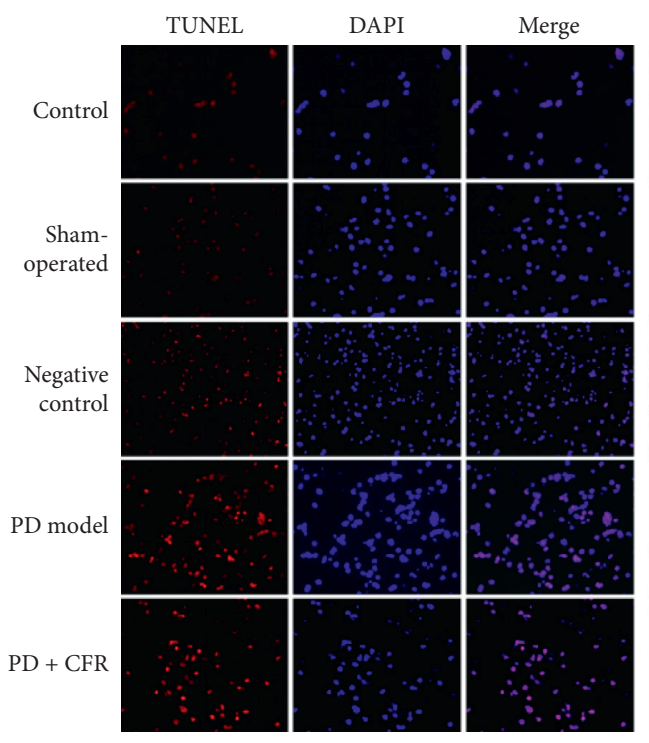

Substantia nigra

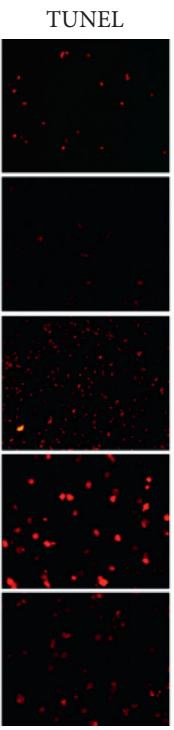

(a)

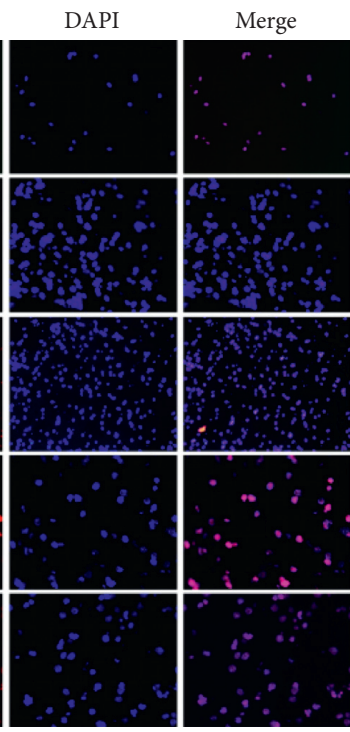

Striatum

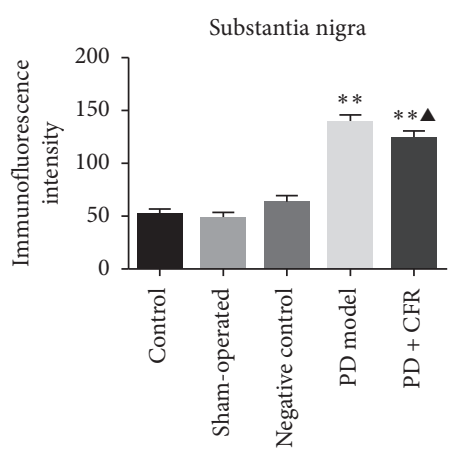

(b)

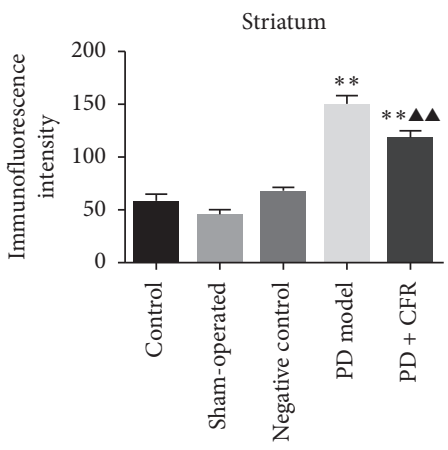

(c)

FIgURE 2: TUNEL assay for the effect of CFR on $\alpha$-syn-induced apoptosis in the substantia nigra and striatum of the PD rat brain tissues (magnification, $\times 200$ ). Control group: without any surgical procedures or treatment, sham-operated group: $0.2 \%$ vitamin $c$, negative control group: AAV empty vector, PD model group: AAV- $\alpha$-syn, and PD + CFR group: AAV- $\alpha$-syn + CFR, 9 ml $/ \mathrm{kg}, 2$ times/d, 6 weeks. 


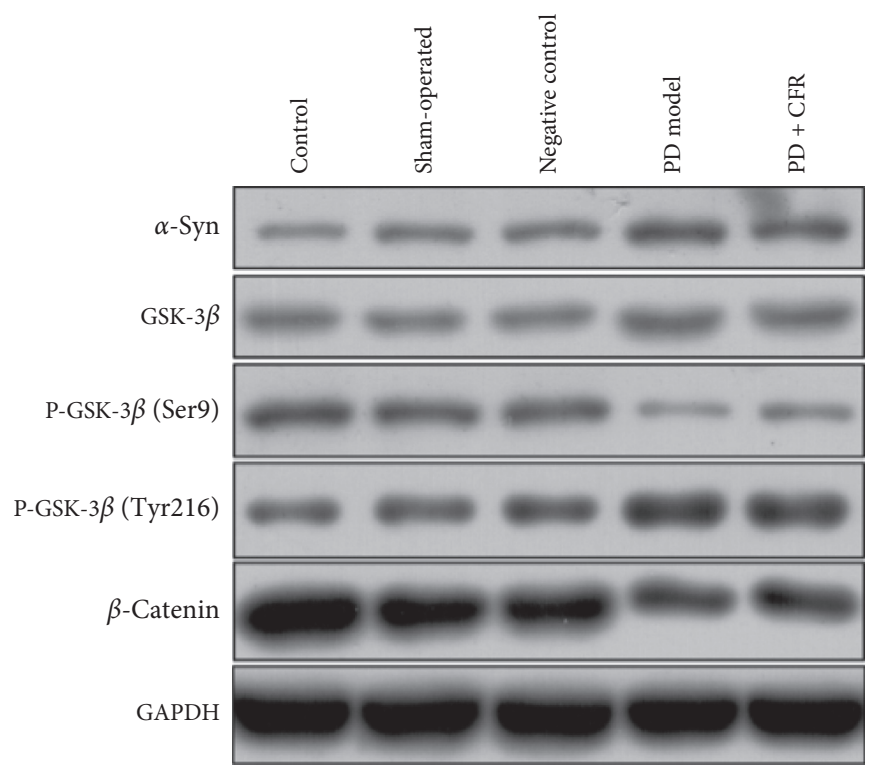

(a)

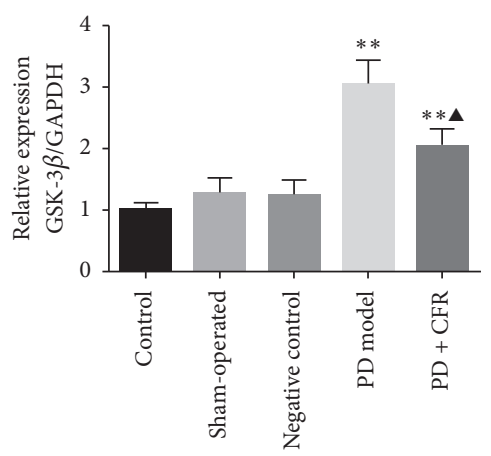

(c)

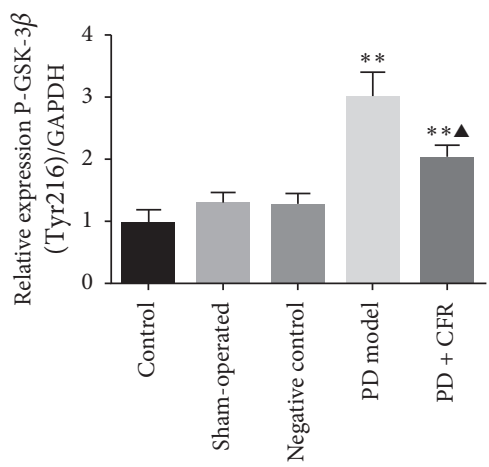

(e)

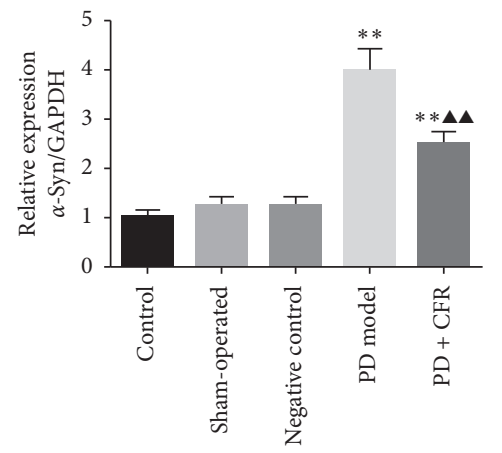

(b)

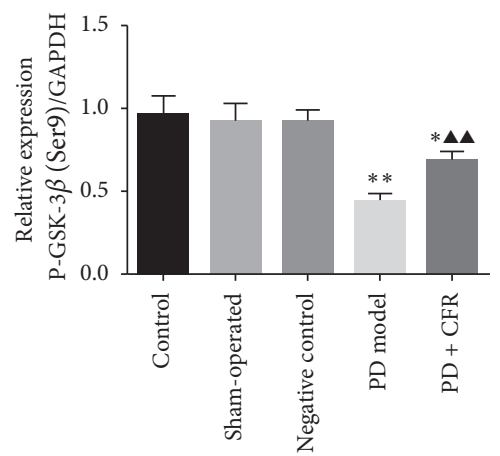

(d)

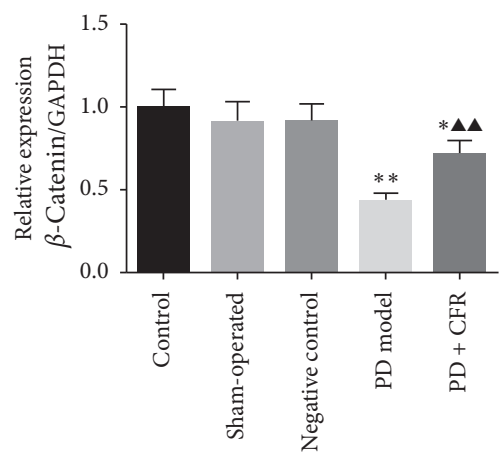

(f)

Figure 3: Effect of CFR on the protein expression of $\alpha$-syn, GSK-3 $\beta$, P-GSK-3 $\beta$ (Ser9), P-GSK-3 $\beta$ (Tyr216), and $\beta$-catenin in rat brain tissues. Control group: without any surgical procedures or treatment, sham-operated group: $0.2 \%$ vitamin $\mathrm{c}$, negative control group: AAV empty vector, PD model group: AAV- $\alpha$-syn, and PD + CFR group: AAV- $\alpha$-syn + CFR, $9 \mathrm{ml} / \mathrm{kg}, 2$ times/d, 6 weeks. Protein expression was determined using western blot, and GAPDH was used as a control. Compared with the control group, ${ }^{*} P<0.05$ and ${ }^{* *} P<0.01$; compared with the PD model group, $\mathbf{\Delta} P<0.05$ and ${ }^{\mathbf{\Delta}} P<0.01$.

$\alpha$-syn, GSK-3 $\beta$, P-GSK-3 $\beta$ (Ser9), P-GSK-3 $\beta$ (Tyr216), and $\beta$-catenin in experiment groups. As shown in Figure 3 , there were no significant differences for the protein expression of $\alpha$-syn, GSK- $3 \beta$, P-GSK-3 $\beta$ (Ser9), P-GSK-3 $\beta$ (Tyr216), and $\beta$-catenin among the control group, sham-operated group, and negative control group. $\alpha$-Syn relative protein expression in the PD model group was increased significantly compared with the control group $(P<0.01)$, and after 6 weeks of treatment with CFR in PD rats, $\alpha$-syn expression was decreased significantly $(P<0.01)$. Similar tendency was also detected for the GSK-3 $\beta$ expression in groups. GSK-3 $\beta$ expression was significantly increased in the PD model 
group compared with the control group $(P<0.01)$, and with CFR administration in $\mathrm{PD}$ rats, the protein expression was decreased significantly $(P<0.05)$ compared to the PD model group. For P-GSK-3 $\beta$ (Ser9) and P-GSK-3 $\beta$ (Tyr216), opposite expression among the groups was observed. P-GSK$3 \beta$ (Ser9) was significantly low-expressed in the PD model group compared with the control group $(P<0.01)$, and this decreased expression was increased in the $\mathrm{PD}+\mathrm{CFR}$ treatment group $(P<0.01)$; compared with the control group, P-GSK-3 $\beta$ (Tyr216) expression was significantly increased in the PD model group $(P<0.01)$, and this expression level was inhibited in the $\mathrm{PD}+\mathrm{CFR}$ treatment group $(P<0.05)$. The relative expression of $\beta$-catenin in the PD model group was significantly decreased compared with the control group $(P<0.01)$, and CFR administration into PD model rats significantly increased the expression of $\beta$-catenin $(P<0.01)$.

3.4. Effect of CFR on the SK-N-SH Cell Viability. After transfected with $\alpha$-syn and incubated with $\mathrm{H}_{2} \mathrm{O}_{2}$, SK-N-SH cells were further treated with CFR for $24 \mathrm{~h}$ or $48 \mathrm{~h}$, and CCK8 assay was used to assess the effect of CFR on cell viability. It could be observed that the cell viability in the $\mathrm{H}_{2} \mathrm{O}_{2}$ group decreased significantly compared with the control group in $24 \mathrm{~h}$ and $48 \mathrm{~h}$ incubation $(P<0.05$, Figure 4). For $24 \mathrm{~h}$ of treatment with CFR in different dosages, the result showed that the cell viability in both $\mathrm{H}_{2} \mathrm{O}_{2}+\mathrm{CFR}-$ $\mathrm{L}$ and $\mathrm{H}_{2} \mathrm{O}_{2}+\mathrm{CFR}-\mathrm{H}$ groups increased compared with the $\mathrm{H}_{2} \mathrm{O}_{2}$ group; however, no significant differences were observed. For $48 \mathrm{~h}$ of treatment with CFR in different dosages, the result showed that the cell viability in both $\mathrm{H}_{2} \mathrm{O}_{2}+\mathrm{CFR}-$ $\mathrm{L}$ and $\mathrm{H}_{2} \mathrm{O}_{2}+\mathrm{CFR}-\mathrm{H}$ groups increased significantly compared with the $\mathrm{H}_{2} \mathrm{O}_{2}$ group $(P<0.05$ and $P<0.01$, respectively).

3.5. Effect of CFR on the Apoptosis of SK-N-SH Cells. TUNEL assay was performed to detect the effect of CFR on SK-N-SH cell apoptosis for $48 \mathrm{~h}$ treatment (Figure 5). Compared with the scarcely observed TUNEL-positive cells in the control group, TUNEL-positive cells in the $\mathrm{H}_{2} \mathrm{O}_{2}$ group were obviously increased, with high fluorescence intensity and amounts. After the CFR treatment, TUNELpositive cells were decreased, and SK-N-SH cell apoptosis was inhibited in the $\mathrm{H}_{2} \mathrm{O}_{2}+$ CFR-L group and $\mathrm{H}_{2} \mathrm{O}_{2}+\mathrm{CFR}-$ $\mathrm{H}$ group, especially in the $\mathrm{H}_{2} \mathrm{O}_{2}+\mathrm{CFR}-\mathrm{H}$ group compared with $\mathrm{H}_{2} \mathrm{O}_{2}$-treated cells.

3.6. Effect of CFR on the Expression of $\alpha-S y n$ in SK-N-SH Cells. The effect of CFR on the expression of $\alpha$-syn in SK-N-SH cells was also evaluated; the immunofluorescence results are shown in Figure 6 . It could be found that $\alpha$-syn was weakly expressed in the control group but was highly expressed in cytoplasm of the $\mathrm{H}_{2} \mathrm{O}_{2}$ group $\mathrm{SK}-\mathrm{N}-\mathrm{SH}$ cells, and the fluorescence intensity was significantly increased compared with the control group. In CFR treatment groups, low dose and high dose of CFR significantly decreased the fluorescence intensity of $\alpha$-syn compared with the $\mathrm{H}_{2} \mathrm{O}_{2}$ group.

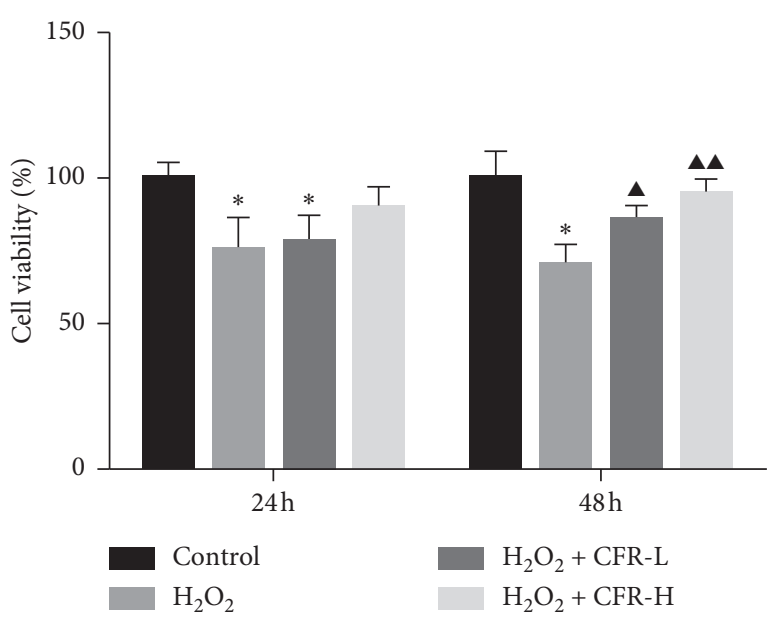

FIgUre 4: Effect of CFR on the SK-N-SH cell viability. Control group: transfected with empty control plasmids, $\mathrm{H}_{2} \mathrm{O}_{2}$ group: transfected with $\alpha$-syn plasmids and $300 \mu \mathrm{M} \mathrm{H}_{2} \mathrm{O}_{2}, \mathrm{H}_{2} \mathrm{O}_{2}+\mathrm{CFR}-\mathrm{L}$ group: transfected with $\alpha$-syn plasmids, $300 \mu \mathrm{M} \mathrm{H}_{2} \mathrm{O}_{2}$, and $5 \%$ CFR, and $\mathrm{H}_{2} \mathrm{O}_{2}+\mathrm{CFR}-\mathrm{H}$ group: transfected with $\alpha$-syn plasmids, $300 \mu \mathrm{M} \mathrm{H}_{2} \mathrm{O}_{2}$, and $10 \%$ CFR. Compared with the control group, ${ }^{*} P<0.05$ and ${ }^{* *} P<0.01$; compared with the $\mathrm{H}_{2} \mathrm{O}_{2}$ group, $\triangle P<0.05$ and ${ }^{\boldsymbol{\Lambda}} \mathrm{P}<0.01$.

3.7. Effect of CFR on the Protein Expression of $\alpha-S y n, G S K-3 \beta$, $P-G S K-3 \beta$, and $\beta$-Catenin in SK-N-SH Cells. As shown in Figure 7 , the protein expression of $\alpha$-syn, GSK- $3 \beta$, and P-GSK-3 $\beta$ (Tyr216) in the $\mathrm{H}_{2} \mathrm{O}_{2}$ group was significantly increased compared with the control group $(P<0.01)$, while the protein expression of P-GSK- $3 \beta$ (Ser9) and $\beta$-catenin in the $\mathrm{H}_{2} \mathrm{O}_{2}$ group was significantly decreased compared with the control group $(P<0.01)$. Comparing these in the $\mathrm{H}_{2} \mathrm{O}_{2}$ group, the protein expression of $\alpha$-syn, GSK- $3 \beta$, and P-GSK$3 \beta$ (Tyr216) in the $\mathrm{H}_{2} \mathrm{O}_{2}+$ CFR-L group and $\mathrm{H}_{2} \mathrm{O}_{2}+\mathrm{CFR}-\mathrm{H}$ group was significantly decreased $(P<0.05$ and $P<0.01$, respectively); and the protein expression of P-GSK-3 $\beta$ (Ser9) and $\beta$-catenin in the $\mathrm{H}_{2} \mathrm{O}_{2}+$ CFR-L group and $\mathrm{H}_{2} \mathrm{O}_{2}+\mathrm{CFR}$ $\mathrm{H}$ group was significantly increased $(P<0.05$ and $P<0.01$, respectively).

\section{Discussion}

As a common neurodegenerative disease, the diagnosis and management of $\mathrm{PD}$ remain challenging, and the choice of the drugs is still limited. Based on the critical role of DA in PD pathogenesis, neuroscientists revealed that PD could be reversed temporarily by pharmacologic interventions to restore dopaminergic neurotransmission [14]. As an intermediate in the pathway of dopamine synthesis, L-Dopa eventually becomes accepted as the preferred treatment for $\mathrm{PD}$, but the adverse effects, dyskinesias, also occur in up to one-third of patients taking L-Dopa eventually $[4,15]$. At the same time, more and more efforts have been made on exploring the new therapeutic strategies including gene therapy and stem cell transplantation therapy with the advances in the medical management, but the long-term curative effects and high cost also restrict the well clinical application of these therapies $[16,17]$. 


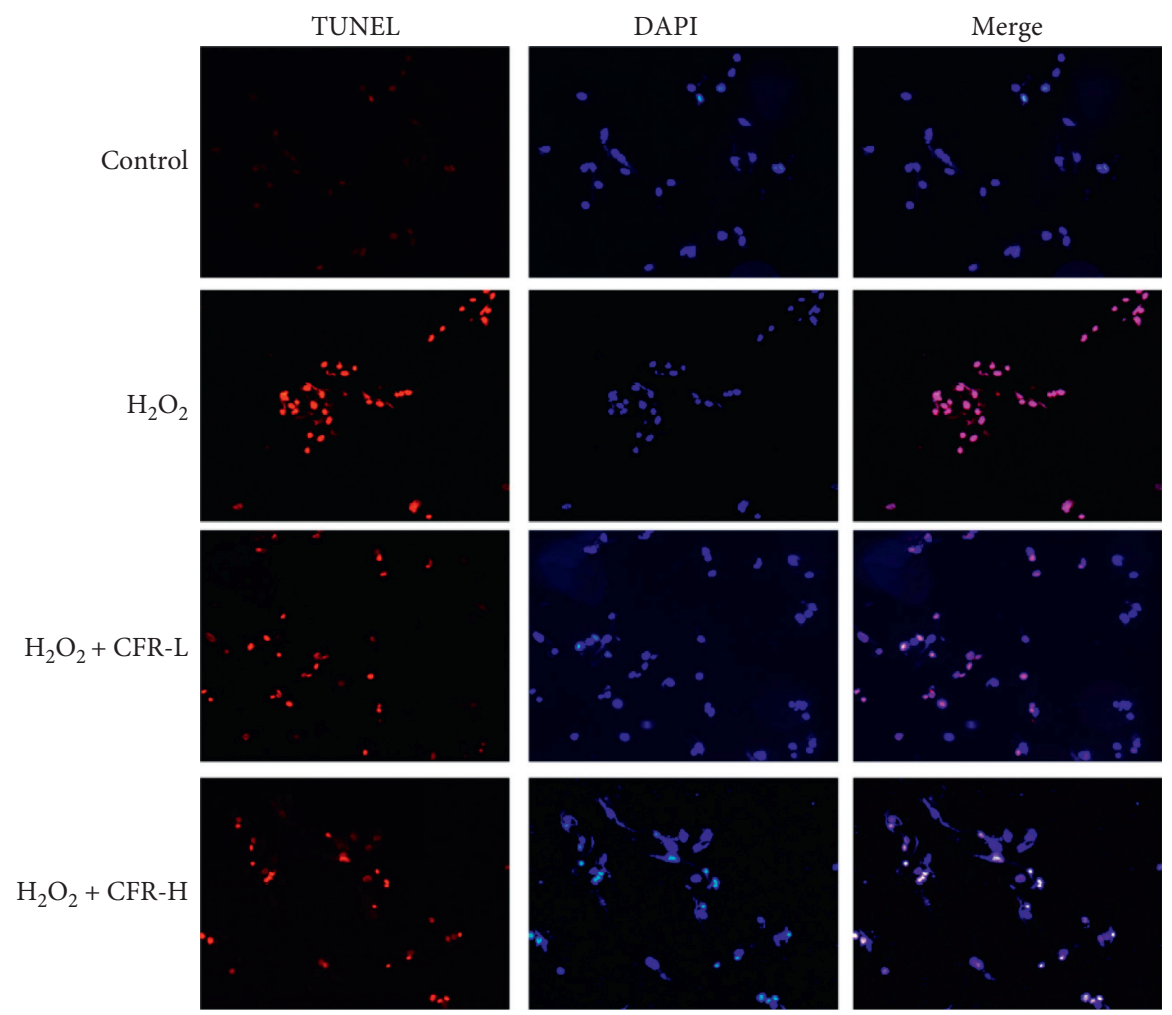

Figure 5: TUNEL assay for the effect of CFR on the apoptosis of the SK-N-SH cells (magnification, $\times 200$ ). Control group: transfected with empty control plasmids, $\mathrm{H}_{2} \mathrm{O}_{2}$ group: transfected with $\alpha$-syn plasmids and $300 \mu \mathrm{M} \mathrm{H}_{2} \mathrm{O}_{2}, \mathrm{H}_{2} \mathrm{O}_{2}+$ CFR-L group: transfected with $\alpha$-syn plasmids, $300 \mu \mathrm{M} \mathrm{H}_{2} \mathrm{O}_{2}$, and 5\% CFR, and $\mathrm{H}_{2} \mathrm{O}_{2}+\mathrm{CFR}-\mathrm{H}$ group: transfected with $\alpha$-syn plasmids, $300 \mu \mathrm{M} \mathrm{H}_{2} \mathrm{O}_{2}$, and $10 \%$ CFR.

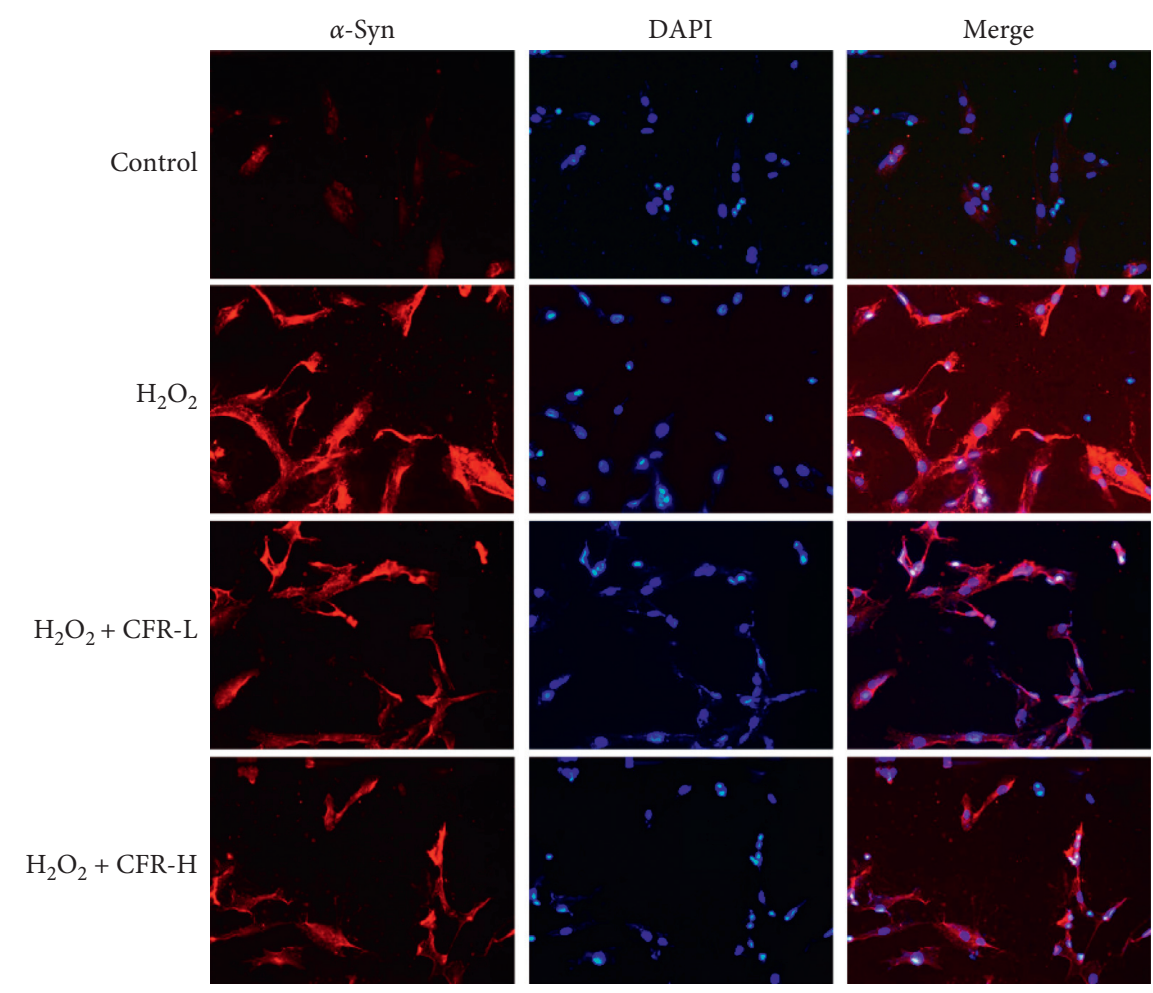

Figure 6: Expression of $\alpha$-syn in SK-N-SH cells after the CFR treatment (magnification, $\times 200$ ). Control group: transfected with empty control plasmids, $\mathrm{H}_{2} \mathrm{O}_{2}$ group: transfected with $\alpha$-syn plasmids and $300 \mu \mathrm{M} \mathrm{H}_{2} \mathrm{O}_{2}, \mathrm{H}_{2} \mathrm{O}_{2}+$ CFR-L group: transfected with $\alpha$-syn plasmids, $300 \mu \mathrm{M} \mathrm{H}_{2} \mathrm{O}_{2}$, and 5\% CFR, and $\mathrm{H}_{2} \mathrm{O}_{2}+\mathrm{CFR}-\mathrm{H}$ group: transfected with $\alpha$-syn plasmids, $300 \mu \mathrm{M} \mathrm{H}_{2} \mathrm{O}_{2}$, and $10 \%$ CFR. 


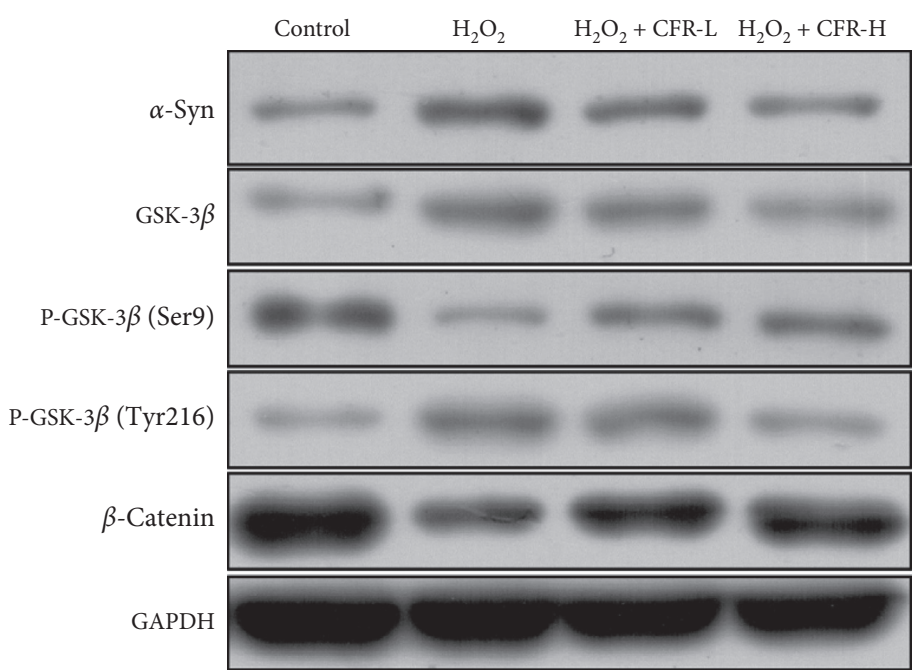

(a)

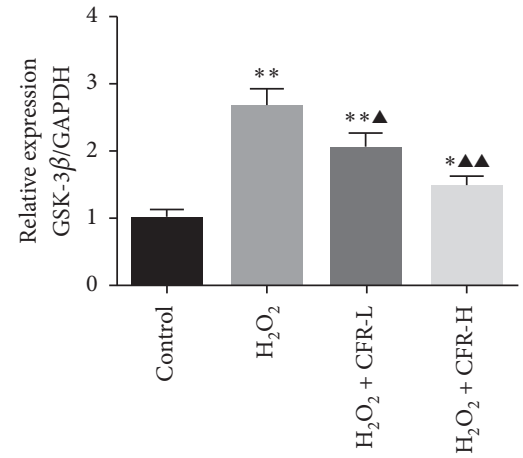

(c)

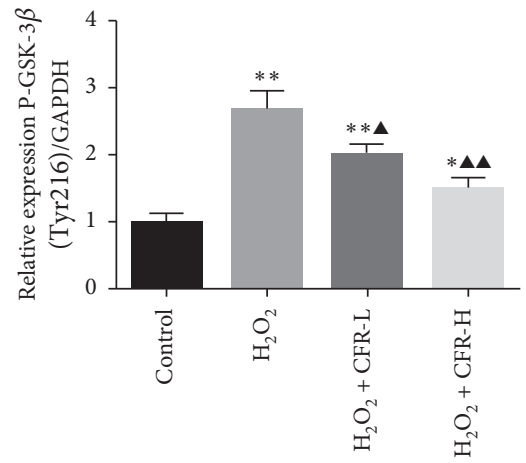

(e)

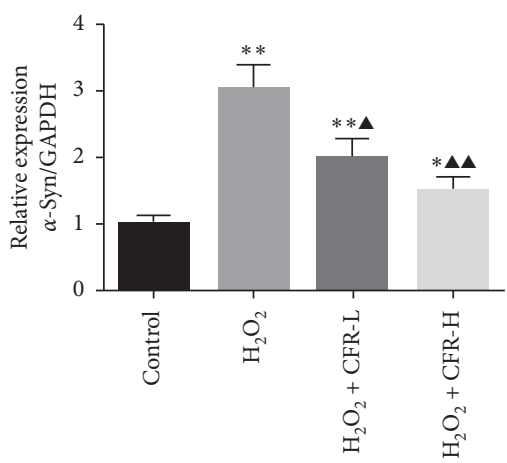

(b)

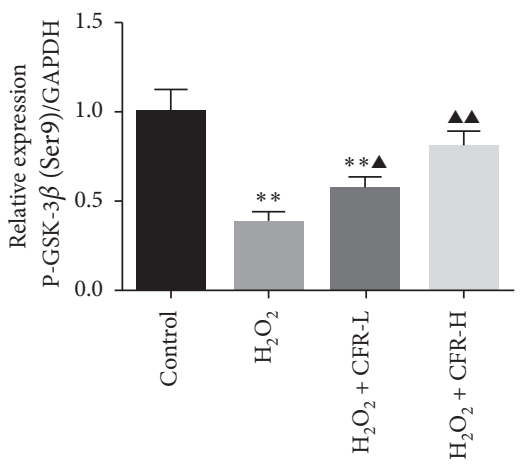

(d)

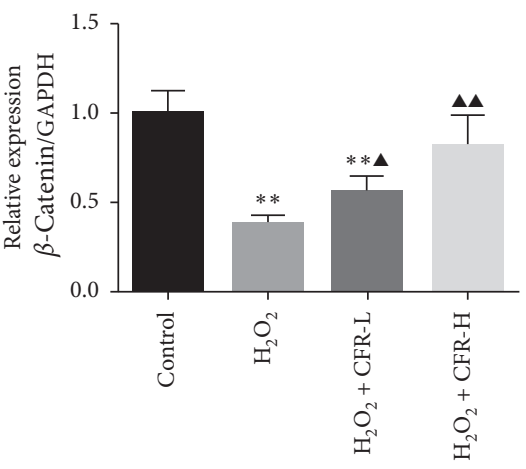

(f)

Figure 7: Effect of CFR on the protein expression of $\alpha$-syn, GSK-3 $\beta$, P-GSK-3 $\beta$ (Ser9), P-GSK-3 $\beta$ (Tyr216), and $\beta$-catenin in SK-N-SH cells. Control group: transfected with empty control plasmids, $\mathrm{H}_{2} \mathrm{O}_{2}$ group: transfected with $\alpha$-syn plasmids and $300 \mu \mathrm{M} \mathrm{H}_{2} \mathrm{O}_{2}, \mathrm{H}_{2} \mathrm{O}_{2}+\mathrm{CFR}-\mathrm{L}$ group: transfected with $\alpha$-syn plasmids, $300 \mu \mathrm{M} \mathrm{H}_{2} \mathrm{O}_{2}$, and $5 \% \mathrm{CFR}, \mathrm{H}_{2} \mathrm{O}_{2}+\mathrm{CFR}-\mathrm{H}$ group: transfected with $\alpha$-syn plasmids, $300 \mu \mathrm{M} \mathrm{H} \mathrm{H}_{2} \mathrm{O}_{2}$, and $10 \%$ CFR. Protein expression was determined using western blot, and GAPDH was used as a control. Compared with the control group, ${ }^{*} P<0.05$ and ${ }^{* *} P<0.01$; compared with the $\mathrm{H}_{2} \mathrm{O}_{2}$ group, ${ }^{\boldsymbol{\Delta}} \mathrm{P}<0.05$ and ${ }^{\boldsymbol{\Lambda}} \boldsymbol{\Delta} P<0.01$.

The objective of the present study is to provide in vivo and in vitro evidence that CFR could be considered as a potential therapeutic agent in the model of PD. In this regard, the neuroprotective properties and possible mechanism of CFR were investigated in the AAV- $\alpha$-syninduced rat model of PD and SK-N-SH cells administrated with $\mathrm{H}_{2} \mathrm{O}_{2}$ and $\alpha$-syn. In accordance with our previous research, the results showed that CFR significantly alleviated the neurotoxicity on PD rats and SK-N-SH cells. Besides, TUNEL assay and immunofluorescence staining assay also indicated that the abnormal accumulation of $\alpha$-syn and increases of cell apoptosis in rats and SK-N-SH cells were also inhibited by CFR, and these regulation effects of CFR on PD might be correlated with the regulation of the GSK-3 $\beta / \beta$-catenin signaling pathway. 
CFR is composed by five traditional Chinese herbs: prepared Rhizoma Rehmannia, Concha Margaritifera Usta, fried Salvia miltiorrhiza, Acorus gramineus Soland, and green tea. Previous study shows that the active compound, salvianolic acid B, from Salvia miltiorrhiza can perform the prophylactic and therapeutic activities against neurodegenerative diseases including PD [18]. Pretreatment with salvianolic acid B in SH-SY5Y cells significantly reduces 6hydroxydopamine- (6-OHDA-) induced generation of reactive oxygen species and prevents 6-OHDA-induced increases in intracellular calcium, which may be effective in treating neurodegenerative diseases [19]. And the tanshinone IIA from Salvia miltiorrhiza promotes the survival of DA neurons in the 1-methyl-4-phenyl-1,2,3,6-tetrahydropyridine (MPTP) mouse model of PD by the suppression of microglial activation and reduced expression of NADPH oxidase and iNOS [20]. Modified Yeoldahanso-tang including Acorus gramineus Soland was reported to have neuroprotective effects in in vivo and in vitro studies; it could inhibit both the loss of tyrosine hydroxylase- ( $\mathrm{TH}-$ ) positive neurons in the SNpc and the reduction of the optical density of tyrosine hydroxylase-immunoreactive (TH-IR) fibers in the striatum in a C57BL/6 mice model of PD [21]. Tea is one of the most consumed beverages worldwide, and multiple studies also prove that tea consumption has an inverse association with PD risk $[22,23]$. Research studies focused on green tea show that the tea polyphenols have the profound neuroprotective and neuroregenerative effects; tea polyphenols do not just possess antioxidant or antichelating properties, but may directly interfere with aggregation of the $\alpha$-syn protein and modulate intracellular signaling pathways, both in in vitro and animal models of PD [24].

In this experiment, overexpression of the disease-inducing protein $\alpha$-syn was introduced for PD modeling. The progression of $\mathrm{PD}$ is mainly due to the degeneration of dopamine neurons in the SNpc. And as a main component of the Lewy bodies in dopamine neurons, abnormal accumulation of $\alpha$-syn is proved to be responsible for the apoptosis of cells and the increasing possibility of neurodegeneration via the formation of the toxic forms like oligomer and polymer of $\alpha$-syn $[25,26]$. A previous study showed that storage, release, and reuptake of DA in the striatum are markedly impaired in $\alpha$-syn-overexpressing DA neurons, suggesting that $\alpha$-syn-induced axonal damage leads to synaptic DA function impairment [27]. Furthermore, different from the toxin-based models, like the injecting of 6OHDA or MPTP in rodent and nonhuman primate animals, overexpression of $\alpha$-syn has provided a novel PD model that recapitulates many features of the human disease. And comparison of the 6-OHDA and $\alpha$-syn rat models in behavioral and histological characteristics revealed that DA neuron loss is prominent in both models, but the AAV$\alpha$-syn model replicates the human pathology more closely than other lesion models [28]. In this study, we used the $\alpha$-syn-overexpressing model for in vivo and in vitro experiments. As shown in the results, the rotation numbers of $\mathrm{PD}$ rats were significantly increased comparing with those in the control group and sham-operated group rats; inhibition of cell viability and promotion of cell apoptosis were also observed in the $\alpha$-syn-induced model group. Besides, the expression of $\alpha$-syn was also elevated in the PD model rat and SK-N-SH cells, indicating the neurotoxicity role of $\alpha$-syn in PD.

Accumulated evidence reveals that the disfunction of GSK- $3 \beta$ and its signaling cascades are directly related to the pathogenesis of neuroinflammation and neurodegenerative disorders [29]. GSK-3 $\beta$ contains two important sites, Ser9 and Tyr216, P-GSK-3 $\beta$ (Ser9) inhibits GSK-3 $\beta$ activity, and P-GSK-3 $\beta$ (Tyr216) promotes GSK-3 $\beta$ activity. Except for the important role in neural development including the regulation of neuronal apoptosis, studies found that GSK-3 $\beta$ has a mutual interaction with $\alpha$-syn, which makes this kinase become an attractive therapeutic target for neurodegenerative disorders. It is reported that PD features such as $\alpha$-syn aggregation and tau hyperphosphorylation induced by rotenone could be reversed by GSK-3 $\beta$, and at the same time, $\alpha$-syn regulates GSK- $3 \beta$ activity by decreasing Ser 9 phosphorylation and elevating Tyr216 phosphorylation to mediate the neurotoxicity $[30,31]$. Study also showed that Axin-2 shRNA- (negative regulator of $\mathrm{Wnt} / \beta$-catenin signaling) mediated upregulation of $\mathrm{Wnt} / \beta$-catenin signaling could enhance the net dopaminergic neurogenesis by improving behavioral functions and mitochondrial biogenesis in the SNpc, reducing apoptotic signaling, autophagy, and ROS generation, and regulating neural genes (Nurr-1, Pitx-3, Ngn-2, and NeuroD1) in PD rats [32]. In the present study, protein expression of GSK-3 $\beta$ and P-GSK$3 \beta$ (Tyr216) was activated, while P-GSK-3 $\beta$ (Ser9) and $\beta$-catenin were inhibited in the PD model group with $\alpha$-syn transferred, which was consistent with the previous study, and CFR administration significantly inhibited the overexpression of $\alpha$-syn, GSK-3 $\beta$, and P-GSK-3 $\beta$ (Tyr216) and also increased the protein expression of P-GSK-3 $\beta$ (Ser9) and $\beta$-catenin.

\section{Conclusions}

In conclusion, the present study was conducted to explore the protective effect of CFR against neurotoxicity and apoptosis induced by $\alpha$-syn in in vivo and in vitro models of PD. As the in vivo study indicated, CFR attenuated the $\alpha$-syn-induced PD rat behaviors with the rotation numbers decreased significantly and inhibited the cell apoptosis in the substantia nigra and striatum tissues of the PD rat brain; the overexpression of $\alpha$-syn was inhibited, and the protein expression of GSK-3 $\beta$, P-GSK-3 $\beta$ (Ser9), P-GSK-3 $\beta$ (Tyr216), and $\beta$-catenin in the GSK-3 $\beta / \beta$-catenin signaling pathway was also regulated by CFR administration. Similar to the in vivo study, the in vitro study showed that CFR significantly improved the cell viability and inhibited SK-N$\mathrm{SH}$ cell apoptosis; the inhibitory effect on $\alpha$-syn and regulatory effect on GSK-3 $\beta$, P-GSK-3 $\beta$ (Ser9), P-GSK-3 $\beta$ (Tyr216), and $\beta$-catenin of the GSK-3 $\beta / \beta$-catenin signaling pathway were also observed in CFR-treated SK-N-SH cells. The present study suggested that CFR may be considered as a potential neuroprotective agent against $\mathrm{PD}$, while further indepth investigation is required. 


\section{Data Availability}

All data generated or analyzed during this study are included within this article.

\section{Conflicts of Interest}

The authors declare that there are no conflicts of interest regarding the publication of this paper.

\section{Acknowledgments}

This study was supported by the Zhejiang Provincial Natural Science Foundation of China (Grant no. LY18H270015), Zhejiang Traditional Chinese Medicine Administration Project (Grant no. 2016ZQ005) and Zhejiang Provincial Special Administration of traditional Chinese medicine in the 13th Five Year Plan-Traditional Chinese Medicine Gerontology Plan.

\section{References}

[1] P. Kermer, A. Köhn, M. Schnieder et al., "BAG1 is neuroprotective in in vivo and in vitro models of Parkinson's disease," Journal of Molecular Neuroscience, vol. 55, no. 3, pp. 587-595, 2015.

[2] J. T. Cavanaugh, T. D. Ellis, G. M. Earhart, M. P. Ford, K. B. Foreman, and L. E. Dibble, "Toward understanding ambulatory activity decline in Parkinson disease," Physical Therapy, vol. 95, no. 8, pp. 1142-1150, 2015.

[3] W. Dauer and S. Przedborski, "Parkinson's disease: mechanisms and models," Neuron, vol. 39, no. 6, pp. 889-909, 2003.

[4] P. A. Lewitt, "Levodopa for the treatment of Parkinson's disease," New England Journal of Medicine, vol. 359, no. 23, pp. 2468-2476, 2008.

[5] D. Savitt and J. Jankovic, "Targeting $\alpha$-synuclein in Parkinson's disease: progress towards the development of diseasemodifying therapeutics," Drugs, vol. 79, no. 8, pp. 797-810, 2019.

[6] M. Nagao and H. Hayashi, "Glycogen synthase kinase-3beta is associated with Parkinson's disease," Neuroscience Letters, vol. 449, no. 2, pp. 103-107, 2009.

[7] B. S. Darshit and M. Ramanathan, "Activation of AKT1/GSK$3 \beta / \beta$-catenin-TRIM11/survivin pathway by novel GSK-3 $\beta$ inhibitor promotes neuron cell survival: study in differentiated SH-SY5Y cells in OGD model," Molecular Neurobiology, vol. 53, no. 10, pp. 1-14, 2015.

[8] Q. Li, D. Zhao, and E. Bezard, "Traditional Chinese medicine for Parkinson's disease: a review of Chinese literature," Behavioural Pharmacology, vol. 17, no. 5-6, pp. 403-410, 2006.

[9] L. Teng, F. Hong, C. Zhang, J He, and H Wang, "Compound formula rehmannia alleviates levodopa-induced dyskinesia in Parkinson's disease," Neural Regeneration Research, vol. 9, no. 4, pp. 407-412, 2014.

[10] M. Decressac, A. Ulusoy, B. Mattsson et al., "GDNF fails to exert neuroprotection in a rat -synuclein model of Parkinson's disease," Brain, vol. 134, no. 8, pp. 2302-2311, 2011.

[11] G. Paxinos and C. Watson, The Rat Brain in Stereotaxic Coordinates, Academic Press, San Diego, CA, USA, 1986.

[12] M. Lazarova, A. Popatanasov, R. Klissurov et al., "Preventive effect of two new neurotensin analogues on Parkinson's disease rat model," Journal of Molecular Neuroscience, vol. 66, no. 4, pp. 552-560, 2018.
[13] K. Singsai, T. Akaravichien, V. Kukongviriyapan, and J. Sattayasai, "Protective effects of streblus asper leaf extract on $\mathrm{H}_{2} \mathrm{O}_{2}$-induced ROS in SK-N-SH cells and MPTP-induced Parkinson's disease-like symptoms in C57BL/6 mouse," Evidence-Based Complementray and Alternative Medicine, vol. 2015, Article ID 970354, 6 pages, 2015.

[14] O. Hornykiewicz, "Dopamine miracle: from brain homogenate to dopamine replacement," Movement Disorders, vol. 17, no. 3, pp. 501-508, 2002.

[15] W. Oertel, K. Eggert, R. Pahwa et al., "Randomized, placebocontrolled trial of ADS-5102 (amantadine) extended-release capsules for levodopa-induced dyskinesia in Parkinson's disease (EASE LID 3)," Movement Disorders, vol. 32, no. 12, pp. 1701-1709, 2017.

[16] T. M. Axelsen and D. P. D. Woldbye, "Gene therapy for Parkinson's disease, an update," Journal of Parkinson's Disease, vol. 8, no. 2, pp. 195-215, 2018.

[17] O. Lindvall, "Clinical translation of stem cell transplantation in Parkinson's disease," Journal of Internal Medicine, vol. 279, no. 1, pp. 30-40, 2016.

[18] R. Zhao, X. Liu, L. Zhang, H. Yang, and Q. Zhang, "Current progress of research on neurodegenerative diseases of salvianolic acid B," Oxidative Medicine and Cellular Longevity, vol. 2019, Article ID 3281260, 9 pages, 2019.

[19] L. L. Tian, X. J. Wang, Y. N. Sun et al., "Salvianolic acid B, an antioxidant from Salvia miltiorrhiza, prevents 6-hydroxydopamine induced apoptosis in SH-SY5Y cells," International Journal of Biochemistry \& Cell Biology, vol. 40, no. 3, p. 422, 2008.

[20] B. Ren, Y. X. Zhang, H. X. Zhou et al., "Tanshinone IIA prevents the loss of nigrostriatal dopaminergic neurons by inhibiting NADPH oxidase and iNOS in the MPTP model of Parkinson's disease," Journal of the Neurological Sciences, vol. 348, no. 1-2, pp. 142-152, 2015.

[21] N. Bae, T. Ahn, S. Chung et al., "The neuroprotective effect of modified Yeoldahanso-tang via autophagy enhancement in models of Parkinson's disease," Journal of Ethnopharmacology, vol. 134, no. 2, pp. 313-322, 2011.

[22] H. Qi and S. Li, "Dose-response meta-analysis on coffee, tea and caffeine consumption with risk of Parkinson's disease," Geriatrics \& Gerontology International, vol. 14, no. 2, pp. 430-439, 2014.

[23] J. L. Barranco Quintana, M. F. Allam, A. S. Del Castillo, and R. F.-C. Navajas, "Parkinson's disease and tea: a quantitative review," Journal of the American College of Nutrition, vol. 28, no. 1, pp. 1-6, 2009.

[24] M. Caruana and N. Vassallo, "Tea polyphenols in Parkinson's disease," Advances in Experimental Medicine and Biology, vol. 863, pp. 117-137, 2015.

[25] M. Zaltieri, J. Grigoletto, F. Longhena et al., " $\alpha$-synuclein and synapsin III cooperatively regulate synaptic function in dopamine neurons," Journal of Cell Science, vol. 128, no. 13, pp. 2231-2243, 2015.

[26] Z. Wang, G. Gao, C. Duan, and H. Yang, "Progress of immunotherapy of anti- $\alpha$-synuclein in Parkinson's disease," Biomedicine \& Pharmacotherapy, vol. 115, Article ID 108843, 2019.

[27] M. Lundblad, M. Decressac, B. Mattsson, and A. Bjorklund, "Impaired neurotransmission caused by overexpression of -synuclein in nigral dopamine neurons," Proceedings of the National Academy of Sciences, vol. 109, no. 9, pp. 3213-3219, 2012.

[28] M. Decressac, B. Mattsson, and A. Björklund, "Comparison of the behavioural and histological characteristics of the 6- 
OHDA and $\alpha$-synuclein rat models of Parkinson's disease," Experimental Neurology, vol. 235, no. 1, pp. 306-315, 2012.

[29] M. Golpich, E. Amini, F. Hemmati et al., "Glycogen synthase kinase-3 beta (GSK-3 $\beta$ ) signaling: implications for Parkinson's disease," Pharmacological Research, vol. 97, pp. 16-26, 2015.

[30] Y.-h. Yuan, W.-f. Yan, J.-d. Sun, J.-y. Huang, Z. Mu, and N.-H. Chen, "The molecular mechanism of rotenone-induced $\alpha$-synuclein aggregation: emphasizing the role of the calcium/ GSK3 $\beta$ pathway," Toxicology Letters, vol. 233, no. 2, pp. 163-171, 2015.

[31] M. Gąssowska, G. A. Czapski, B. Pająk, M. Cieślik, A. M. Lenkiewicz, and A. Adamczyk, "Extracellular $\alpha$-synuclein leads to microtubule destabilization via GSK-3 $\beta$-dependent Tau phosphorylation in PC12 cells," PLoS One, vol. 9, no. 4, Article ID e94259, 2014.

[32] S. Singh, A. Mishra, S. J. Mohanbhai et al., "Axin-2 knockdown promote mitochondrial biogenesis and dopaminergic neurogenesis by regulating $\mathrm{Wnt} / \beta$-catenin signaling in rat model of Parkinson's disease," Free Radical Biology and Medicine, vol. 129, pp. 73-87, 2018. 